\title{
Food-based dietary guidance on iron and vitamin D for 1-5-year-old children in Ireland
}

\author{
O.C. Lyons ${ }^{1,2}$, M.A. Kerr ${ }^{2}$, H. McNulty ${ }^{2}$, F. Ward ${ }^{3}$, J. Walton ${ }^{4}$, M.B.E. Livingstone ${ }^{2}$, I. Saul ${ }^{3}$ \\ and M.A.T. Flynn ${ }^{1,2}$ \\ ${ }^{1}$ Food Safety Authority of Ireland, Dublin, Ireland, \\ ${ }^{2}$ Ulster University, Coleraine, UK, \\ ${ }^{3}$ Children's Health Ireland, Dublin, Ireland and \\ ${ }^{4}$ Cork Institute of Technology, Cork, Ireland
}

Iron and vitamin $\mathrm{D}$ are nutrients of public health importance in young children ${ }^{(1)}$. Iron deficiency is associated with poorer cognitive outcomes which may persist into adulthood ${ }^{(2)}$ and vitamin D deficiency in children can result in nutritional rickets ${ }^{(3)}$. The aim of this study was to develop food-based dietary guidance on iron and vitamin D for 1-5-year-old children.

Secondary analysis of the 2012 Irish National Pre-School Nutrition Survey (NPNS; n 500) identified foods consumed by $>10 \%$ of consumers $>1$ and $\leq 5$ years. Dietary modelling was conducted for boys and girls in six age groups $(1,1.5,2,3,4$ and 5 years) and at five percentiles on the World Health Organisation growth charts (0.4th, 25th, 50th, 75th and 99.6th). The food patterns developed (n 120; n 60 omnivore, n 60 vegetarian) were assessed to identify children at risk of inadequate iron (<average requirement, AR; $5 \mathrm{mg}$ ) and vitamin D (<estimated average requirement, EAR; $10 \mu \mathrm{g}$ ) intakes. Key food sources of iron and vitamin D were identified from the food patterns of children meeting the intake targets and were used in the modelling. In terms of vitamin D, skin synthesis from sunlight exposure was also considered.

Inadequate dietary intakes of iron and vitamin $\mathrm{D}$ were identified in food patterns of $1-3$ and $1-5$-year-olds, respectively. Red meat and iron-fortified cereal ( $>12 \mathrm{mg} / 100 \mathrm{~g})$ were identified as key foods contributing to iron intakes. Inclusion of red meat ( $30 \mathrm{~g}, 3$ days/ week) increased iron intakes by $\sim 0.3 \mathrm{mg} / \mathrm{d}$, whereas iron-fortified cereal ( $30 \mathrm{~g}, 5$ days/week) increased iron intakes by $\sim 1 \mathrm{mg} / \mathrm{d}$. A combination of both red meat and iron-fortified cereal resolved inadequate iron intakes for 1-3-year-olds, except those $<25$ th growth percentile. These children additionally required an iron-fortified milk $(1.2 \mathrm{mg} / 100 \mathrm{~mL})$ or an iron supplement $(7 \mathrm{mg}, 4$ days/week) to resolve inadequacy. For all 1-5-year-olds, vitamin D inadequacy was correctable by including a vitamin D-fortified milk $(2-4.2 \mu \mathrm{g} /$ $100 \mathrm{~mL}$ ) in combination with a daily $5 \mu \mathrm{g}$ vitamin D supplement and consideration of typical sunlight exposure.

Adequate iron intakes can be achieved through inclusion of iron-containing foods (red meat, beans and lentils) and iron-fortified foods (cereal and milks). The EAR for vitamin D can be difficult to achieve from food alone and research has shown that there is a seasonal variation in vitamin D status in this age group ${ }^{(4)}$. Therefore, vitamin D intakes of $\geq 5 \mu \mathrm{g}$ were deemed to be acceptable as the effect of sunlight exposure also needs to be accounted for. This food-based dietary guidance needs to be widely promoted to caregivers to limit the risk of inadequate iron and vitamin D intakes in this age group.

\section{References}

1. European Food Safety Authority (2013) EFSA Journal 11(10), 3408.

2. Lozoff B, Smith JB, Kaciroti N, et al. (2013) J Pediatr 163(5), 1260-6.

3. Munns CF, Shaw N, Kiely M, et al. (2016) J Clin Endocrinol Metab 101(2), 394 415.

4. Ni Chaoimh C, McCarthy EK, Hourihane JO, et al. (2018) Eur J Nutr 57(2), 783-94. 